\title{
Determination of an Equivalent Loading Circle Which May Represent the Loading of the Dual Wheels
}

\author{
Baye Birane Thiam¹, Fatou Samb ${ }^{2}$, Adama Dione ${ }^{1}$ \\ ${ }^{1}$ Laboratoire de Mécanique et Modélisation, UFR Sciences de l'Ingénieur, Université de Thiès, Thiès, Sénégal \\ ${ }^{2}$ Chef Département géotechnique, UFR Sciences de l'Ingénieur, Université de Thiès, Thiès, Sénégal \\ Email: bayebiranet@gmail.com, fatou.samb@univ-thies.sn, adama.dione@univ-thies.sn
}

How to cite this paper: Thiam, B.B., Samb, F. and Dione, A. (2018) Determination of an Equivalent Loading Circle Which May Represent the Loading of the Dual Wheels. Open Journal of Civil Engineering, 8, 234-244.

https://doi.org/10.4236/ojce.2018.82018

Received: April 23, 2018

Accepted: June 26, 2018

Published: June 29, 2018

Copyright $\odot 2018$ by authors and Scientific Research Publishing Inc. This work is licensed under the Creative Commons Attribution International License (CC BY 4.0).

http://creativecommons.org/licenses/by/4.0/

\begin{abstract}
This work aims to look for a simplifying surface that can represent the effect of the dual wheels on the variation of the stress and deformation state prevailing during the passage of traffic loads. This was facilitated by the results of Thiam (2016) [4] obtained on the distribution of the vertical contact stress in the space described by the dual wheels. The analysis of the results of this study, on all the loading circles considered, shows that the radius loading circle equal to $0.181 \mathrm{~m}$ makes it possible to most probably represent the effect of the dual wheels. With this new surface, the effect of the dual wheels can be determined in 2D. The choice of this load is confirmed by a study in case of overload. Thus, the single axle with dual wheels is represented by a simplified diagram equipped on each side by a disk of radius $0.181 \mathrm{~m}$. These results are obtained using a numerical simulation under Cast $3 \mathrm{M}$ with a gravelly lateritic pavement.
\end{abstract}

\section{Keywords}

Dual Wheels, Circular Surface, Equivalent Loading Circle, Single Axle with Dual Wheels, Lateritic Gravelly, Cast3M

\section{Introduction}

The concept of equivalent single-wheel load has long been used in the structural design of the pavement. In order to design the exchange of these loads at the equivalent single wheel load (ESWL), calculation methods have been proposed by some authors like [1] and [2]. These methods are particular adapted to the design of airport pavements. The rapidly changing configuration of heavy 
trucks, equipped with multiple wheels, has highlighted the need for a pavement design method, according to which multi-wheel loading can be linked to a common standard independent of the configuration of the road wheel. In many cases, the loading of the dual wheels is described by two circles with a radius of $0.125 \mathrm{~m}$ and a center distance of $0.375 \mathrm{~m}$. The configuration of this load (2 disks spaced) does not allow to model the whole structure-loading in $2 \mathrm{D}$ [3]. The simplification of this loading into an equivalent single load; provides pavement designers with a practical means of analysis and to evaluate the state of stress and deformation at the level of the roadway. The load circles are converted to a surface equivalent to a single loading circle so that the design criteria based on the single-wheel loading circle can still be applied. This will allow us to have the effect of dual wheels in 2D with the new radius. Although further research is needed in this direction, the simplification method presented here will provide a satisfactory solution to the problem of loading wheels coupled to a loading circle. The studies conducted as part of this work are essentially based on a numerical simulation using the Cast $3 \mathrm{M}$ finite element calculation code.

\section{Modeling the Effect of the Dual Wheels on Pavement Behavior}

The study of the distribution of the vertical contact stress in 3D space by [4] has a particular advantage for the realization of this research. This distribution is performed with the loading of the dual wheels described by 2 disks with a radius of $0.125 \mathrm{~m}$ and a distance of $0.375 \mathrm{~m}$ and that of a wheel simple radius $0.125 \mathrm{~m}$ on lateritic pavements. The results of his studies show that the vertical contact stress is non-uniform on the circular footprint and has a significant influence on the deformation of the pavement at the level of the bituminous layer. This deformation is maximum in the center of the circular imprint where the vertical stress is maximum. The distribution of the vertical contact stress does not influence the platform [4]. This non-uniformity has been shown by [5] under a pneumatic tire thanks to the VRSPTA system (Vehicle-Road Surface Pressure Transducer Array) according to the intensity of the load and the inflation pressure. These results show that it is possible to determine non-uniform distributions of the vertical contact stress for modeling to evaluate their effect. In other words, the results obtained with the semi-axle with dual wheels are of particular interest for the size of roadways. The stresses induced in the structure by the load are maximum in the center of each circular imprint but not in the center of gravity of the half-axle (or plumb the twinning) [4]. The implementation of these previous results allows us to approach the notion of an equivalent surface.

\section{Study of an Equivalent or Simplifying Surface}

Modeling the load of a half-axle of reference shows the non-uniformity of the vertical contact stress on the footprint of dual wheels. This allowed us to quantify the maximum deformation of the roadway. This deformation is maximum in 
the center of each twinning disk. The study of an equivalent surface consists in looking for a single circle of loading to simulate in the most probable or approximate manner the effects of vertical stress on the footprint of dual wheels.

For this, we consider two (2) cases of loadings which are described as follows: Figure 1.

- The load 1 is a circle of radius equal to $0.312 \mathrm{~m}$ whose center is the middle of the center distance. This circle is tangent to each twinning disk, and this circle represents a circumscribed circle for the two circular imprints;

- The load 2 is a circle of radius equal to $0.187 \mathrm{~m}$ passing through the center of each twinning disk whose center is midway between the axes.

The evolution of the deformation will be observed at the center of each load. Also, an analysis of the evolution of deformation as a function of depth will be used to better understand the details of the study. For this, we will represent the deformation at each layer of the roadway to know the answer at each level during a solicitation. It is important to emphasize that the study of these loads is done by referring to the evolution of the deformation obtained at the center of a dual wheel. The studies conducted as part of this work are essentially based on a numerical simulation using the Cast3M finite element calculation code.

\subsection{Structure of the Modeled Roadway: Characteristics of the Materials-Geometry of the Model and Mesh-Loadings-Boundary Conditions}

The modeling of a structure leads, in general, is to be interested in several aspects of which the most usual is the geometry and its discretization. The modeling is based on a 3D structure of flexible pavement, consisting of a surface layer made of $80 \mathrm{~mm}$ thick bituminous materials, a lateritic gravelly basecoat treated with $2 \% 250 \mathrm{~mm}$ thick cement, a laterite gravelly foundation layer of $250 \mathrm{~mm}$ thickness and a platform of infinite thickness. The simulations were performed considering the hypothesis of the non-linearity of the base layer and that of the foundation, while the bituminous layer and the platform have a linear behavior. The input parameters obtained by [6] on the lateritic gravel of Ngoundiane are presented in Table 1 and used as a working tool for modeling.

The construction of the finite element model under Cast $3 \mathrm{M}$ is done in this

Table 1. Characteristics of the lateritic gravel of Ngoundiane [6].

\begin{tabular}{ccccccc}
\hline \multirow{2}{*}{ Layers of roadway Thickness $(\mathrm{m})$} & \multicolumn{2}{c}{ Linear model } & \multicolumn{2}{c}{ Parameters of Uzan nonlinear model } \\
\cline { 3 - 7 } & & $v()$ & $\mathrm{E}(\mathrm{MPa})$ & $\mathrm{k}_{1}(\mathrm{KPa})$ & $\mathrm{k}_{2}()$ & $\mathrm{k}_{3}()$ \\
\hline Bituminous & 0.08 & 0.35 & 1300 & - & - & - \\
Base $2 \%$ & 0.250 & 0.25 & 84 & 279074 & 0.65 & -0.56 \\
Raw foundation & 0.250 & 0.25 & 62 & 837276 & 0.13 & -0.33 \\
Platform & 10 & 0.25 & 30 & - & - & -
\end{tabular}




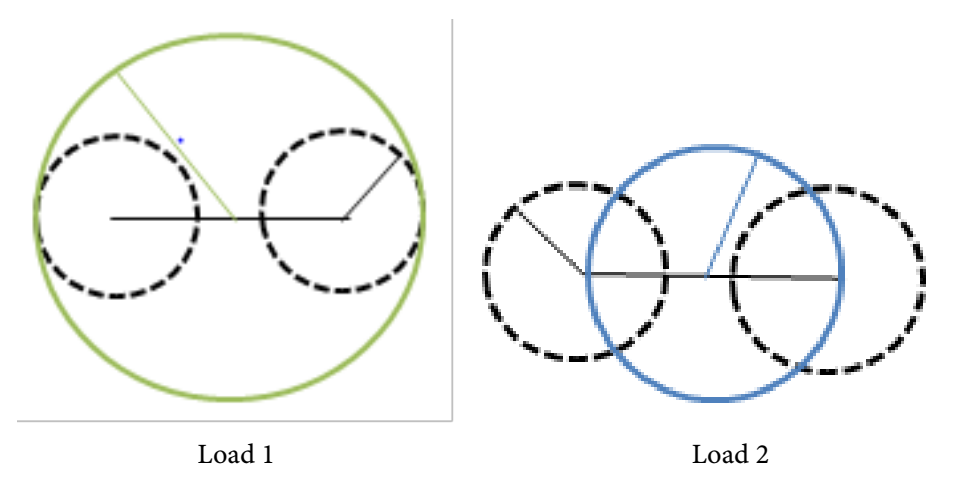

Figure 1. Geometry of the two loads.

study using elements at 8 knots (cub8) on a quarter of the pavement. The carriageway is loaded with a half-axle with the dual wheels spaced $37.5 \mathrm{~cm}$ apart and a single wheel with a radius of $12.5 \mathrm{~cm}$. The charges will be applied to finely meshed fingerprints located at the surface layer. The description of this geometry has been adopted by [7], who referred to the work of [6] for the optimal dimensions chosen. As part of this work, the reference axle is the single dual wheel $130 \mathrm{KN}$, used to represent the reference load during mechanical calculation.

The loading of a half-axle is equal to $65 \mathrm{KN}$. This load will be distributed and applied to the two fingerprints of the dual wheels finely meshed located at the surface layer. For each load considered, the entire load of a reference half-axle is applied. For the boundary conditions, the horizontal displacements are blocked in the transverse directions, and the vertical and horizontal displacements are blocked in the lower part of the platform. The images of the 3D mesh of the roadway for each load considered and that of the dual wheels are given respectively by Figure 2 and Figure 3.

\subsection{Analysis and Interpretation of the Results}

The results obtained using these loadings, at each layer, are presented in Figures $4(\mathrm{a})-4(\mathrm{~d})$.

The results obtained, in the different loading cases, show that the evolution of the deformations differs from one layer to another. It decreases according to the depth of the layer at the level of the roadway. This may be because the effect of the load is attenuated with the depth and distance of the area requested. However, it is important to note that the opposite trend is observed at the bottom of the foundation layer to a certain depth of the platform. This may be related to several factors (material properties, interface phenomenon, etc.) that are not covered in this study. The results of these simulations show that the load 1 is very low to represent the effect of the dual wheels at the two (2) layers of pavement (bituminous layer, base layer). By contrast to the load 2, the evolution of the deformation is close to that obtained with the dual wheels. This is related to the size of the loading circle. As the applied load remains the same, the stress is accentuated with the reduction of the surface of the loading circle. From the load 2, 


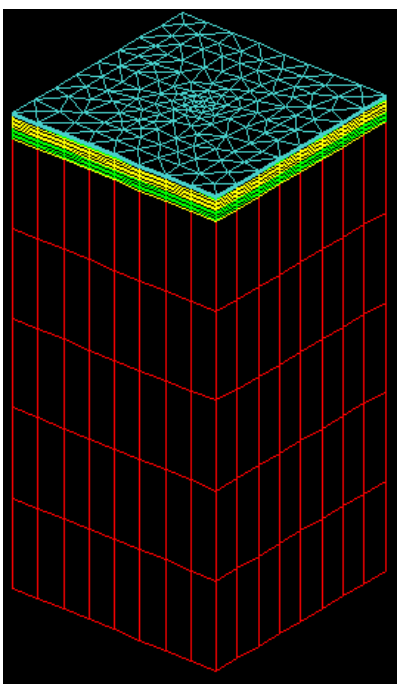

(a)

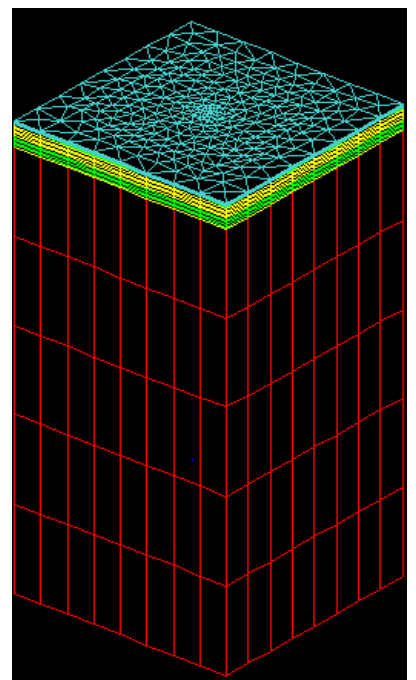

(b)

Figure 2. Mesh of the structure roadway with the loadings; (a) load 1 and (b) load 2.

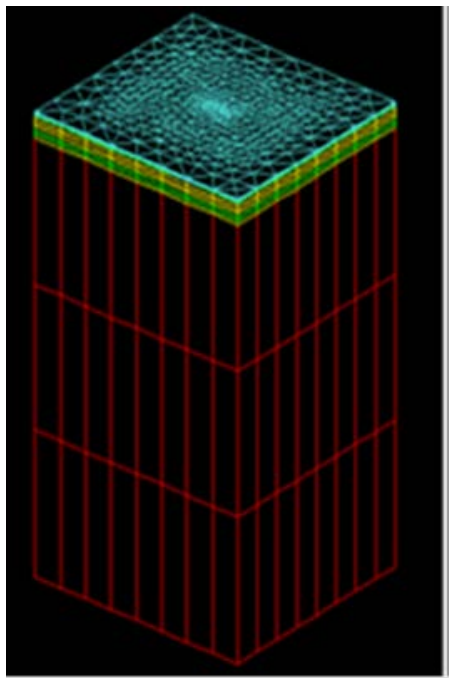

Figure 3. Mesh of the structure roadway with the loading of dual wheels [7]

we study a variation of the radius towards the loading center (that is to say a decrease of the radius) to see if there is another surface closer than that of the loading 2. Figures 5(a)-5(d) show the results obtained with the different radius considered.

It can be seen from these results that, for the different loading circles considered, the evolution of the deformation is the same at the level of the base layer, the foundation and the platform. However, there is a deformation gap at the level of the bituminous layer with the different circles of loadings. With the radius loading circle equal to $0.181 \mathrm{~m}$, the maximum deformation obtained at the surface of the bituminous layer corresponds to that obtained with the dual wheels for this layer. The evolution of the latter is similar and close to that observed with dual wheels. The difference between the two deformations can be expressed 


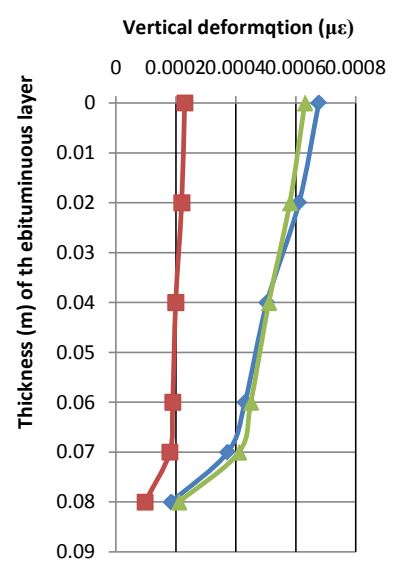

(a)

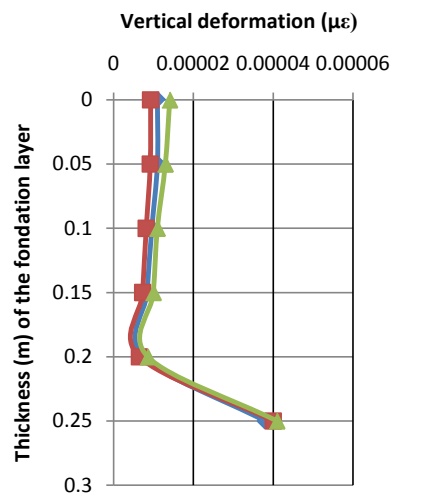

(c)

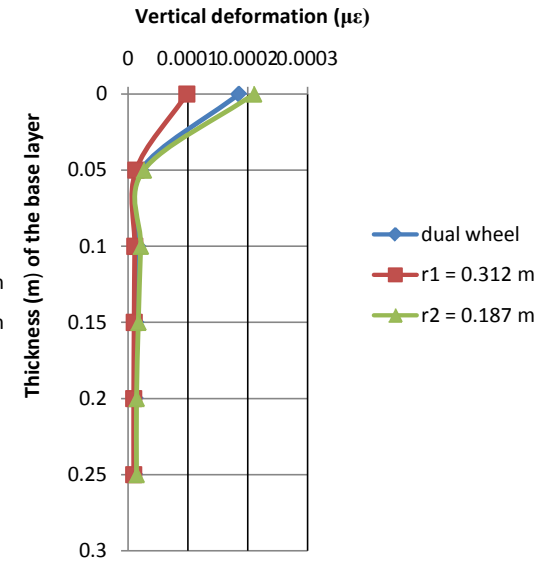

(b)

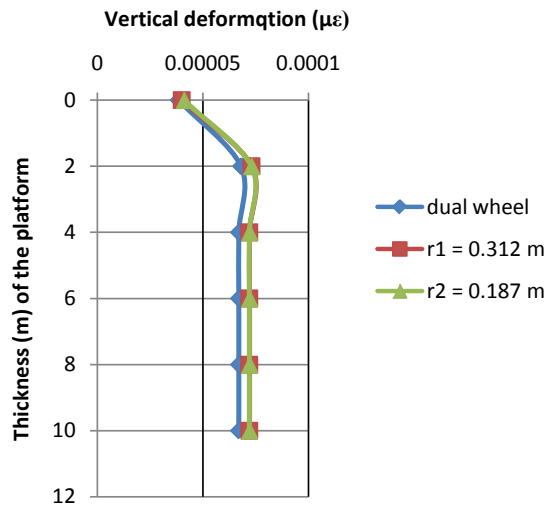

(d)

Figure 4. Evolution of the vertical deformation with the loadings studied at the level: (a) bituminous layer; (b) base layer; (c) foundation layer; (d) platform.

in relative error according to the formula of equation 1.

$$
\text { Relative error (\%) } \frac{\text { Present value }- \text { Reference value }}{\text { Reference value }} \times 100
$$

Table 2 summarizes the relative error on the deformation in the different layers between the radius loading circle equal to $0.181 \mathrm{~m}$ and the loading of dual wheels

It should be noted that these relative errors are common with the other load circles studied. The difference between the different loading circles is found on the deformation obtained at the surface of the bituminous layer.

That's why our choice will be on the $0.181 \mathrm{~m}$ radius loading circle to represent the effect under the dual wheels footprint. This loading will be noted the loading 3 for the rest of the work whose image of the geometry is given by Figure 6 . Figure 7 presents the mesh of the structure with this loading.

Otherwise, [8] also show that a $44 \%$ increase in load leads to a $15 \%$ to $20 \%$ increase in deformation for single wheels and $20 \%$ to $30 \%$ for dual wheels. The damage does not only depend on the weight of the vehicle, but also on the configuration of the loads transmitted to the road [9]. [6] shows that it is possible to 
Vertical deformation $(\mu \varepsilon)$

o 0.00020 .00040 .00060 .0008

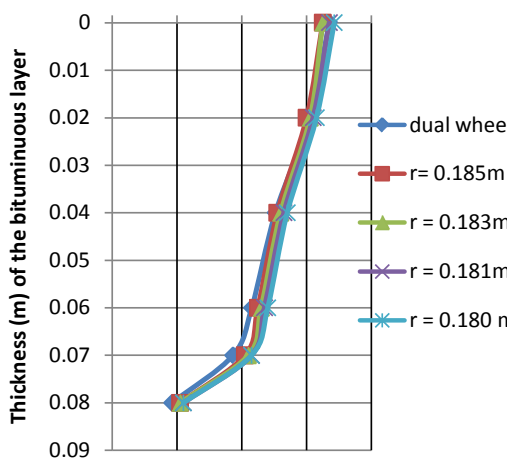

(a)

Vertical deformation $(\mu \varepsilon)$

$0 \quad 0.000020 .000040 .00006$

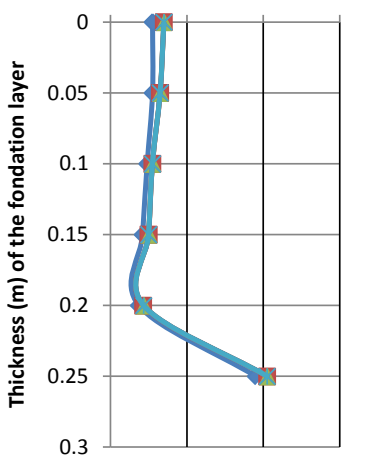

(c)
Vertical deformation $(\mu \varepsilon)$

$\begin{array}{ll}0 & 0.00010 .00020 .0003\end{array}$

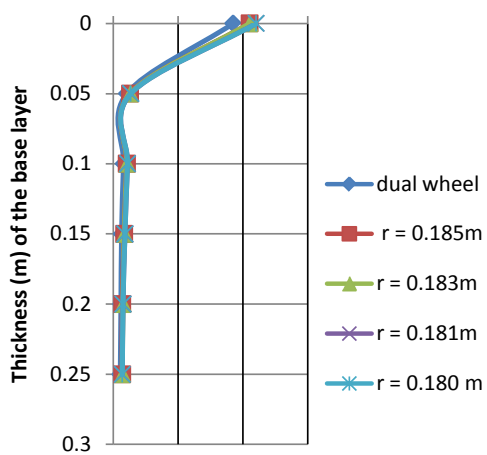

(b)

Vertical deformation $(\mu \varepsilon)$

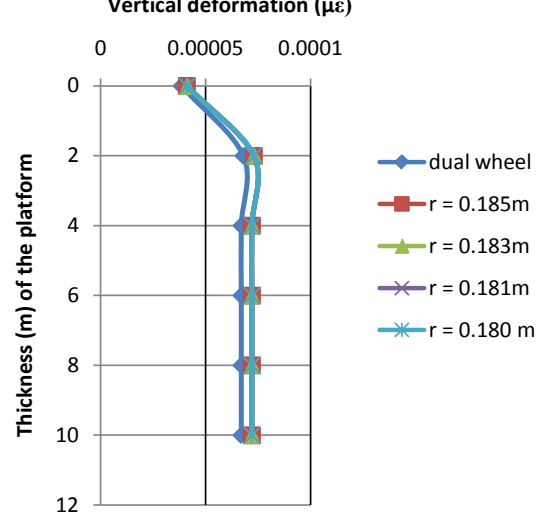

(d)

Figure 5. Evolution of the vertical deformation with the variation of the radius of the loading circle at the level of: (a) bituminous layer; (b) base layer; (c) foundation layer; (d) platform

Table 2. Relative error on the deformation at the level of the layers with the reference load.

\begin{tabular}{cccc}
\hline Level & Roof of the base layer & $\begin{array}{c}\text { Roof of the } \\
\text { foundation layer }\end{array}$ & Roof of the platform \\
\hline Relative error (\%) & 13 & 22 & 8 \\
\hline
\end{tabular}

predict the impact of the overload on the deformations and the deflections at the level of the roadway. So it is also important to study the evolution of the deformation with the load 3 in case of overload. For this, we consider a total load of a single axle with dual wheels equal to 20 tons. Half of this load (100 kN) will be applied at the level of the loading 3. This half of the load will be distributed on the two disks representing the half-axle to be able always to make a comparison between the two loadings. Figures $8(a)-(8 d)$ show the results obtained in case of overload.

The analysis of these results shows that even in case of overload, the evolution of the deformation obtained with the load 3 is very close and similar to that of 


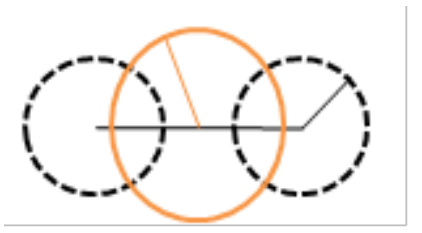

Figure 6. Schematic of the loading 3.

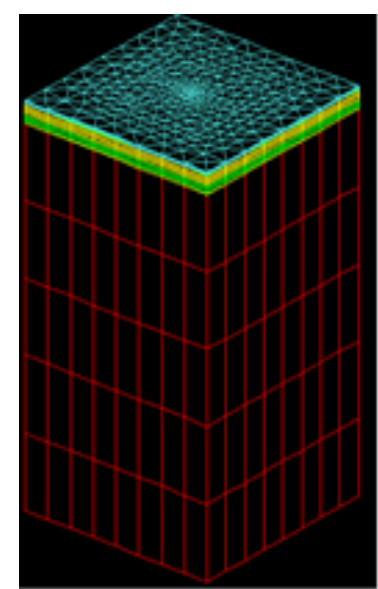

Figure 7. Meshing of the structure with loading 3.

the dual wheels. This allows us to confirm our choice on the load 3. The relative error in case of overload is presented in Table 3.

By these facts, the footprint of the dual wheels of a half-axle, described with the aid of two $0.125-\mathrm{m}$ disks, of $0.375 \mathrm{~m}$ between-axis, can be represented by a single circular surface of equal radius at $0.181 \mathrm{~m}$ (load 3). Given the non-uniformity of the vertical contact stress on the dual wheels footprint, this new surface will represent the effect under the center of a pairing disk where the vertical contact stress is maximum. Therefore this equivalent surface will allow us to determine the effect of the dual wheels on the behavior of pavements in 2D.

Thus, in the space of $3 \mathrm{D}$, the single axle with the dual wheels can be represented by two circles of radius equal to $0.181 \mathrm{~m}$. The loading of the dual wheels is represented with a single disk. So axle will be equipped on each side by a disk of radius $0.181 \mathrm{~m}$.

According to [10], the distance between the two centers is $1830 \mathrm{~m}$. The new geometry of the axle with the equivalent surface is represented by Figure 9 .

The mesh obtained, with the simplified loading of the single axle with the dual wheels, is shown in Figure 10.

\section{Conclusion}

In three-dimensional space, [4] has shown that vertical deformation is maximal at the center of each disk in the space described by the pairing of two disks of $0.125 \mathrm{~m}$ and $0.375 \mathrm{~m}$ between-axis. In order to find a loading circle, which can 
Vertical deforformation $(\mu \varepsilon)$

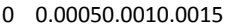

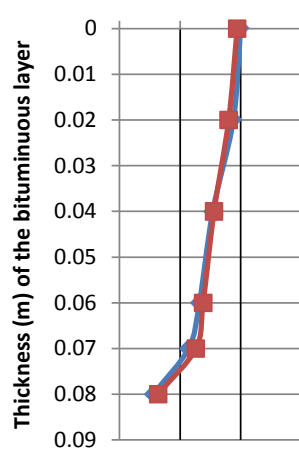

(a)

Vertical deformation $(\mu \varepsilon)$

$\begin{array}{ll}0 & 0.000020 .000040 .00006\end{array}$

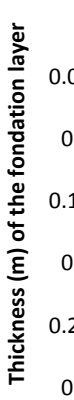

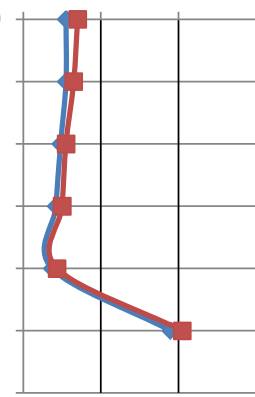

(c)
Vertical deformation $(\mu \varepsilon)$

$\begin{array}{lll}0 & 0.0002 & 0.0004\end{array}$

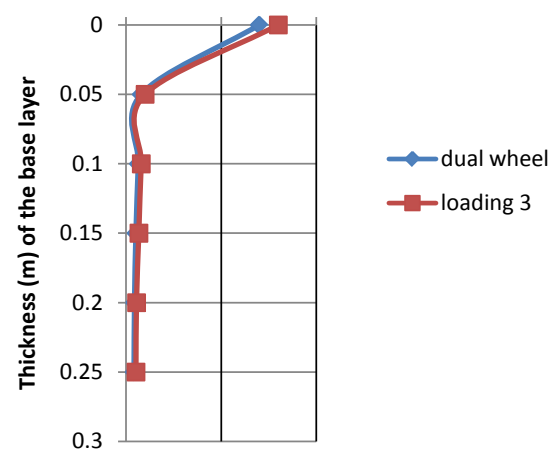

(b)

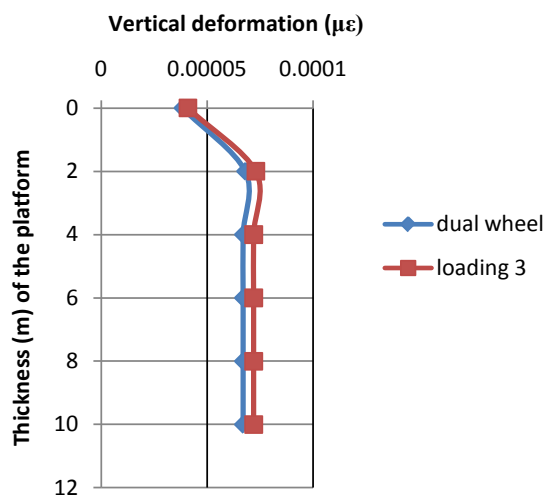

(d)

Figure 8. Evolution of vertical deformation in the event of overload at: (a) bituminous layer; (b) base layer; (c) foundation layer; (d) platform.

Table 3. Relative error on the deformation at the level of the layers in case of overload.

\begin{tabular}{ccccc}
\hline Level & $\begin{array}{c}\text { Surface of the } \\
\text { bituminous layer }\end{array}$ & $\begin{array}{c}\text { Roof of the } \\
\text { base layer }\end{array}$ & $\begin{array}{c}\text { Roof of } \\
\text { the foundation layer }\end{array}$ & $\begin{array}{c}\text { Roof of the } \\
\text { platform }\end{array}$ \\
\hline Relative error (\%) & 3 & 14 & 23 & 8
\end{tabular}

represent the two circles of loadings of the twinned wheels, several circles of loadings considered. By referring to results of [4] obtained under the center of a dual wheel, we note a deformation gap at each layer of the roadway between the different load circles and the dual wheels. This difference is expressed in relative error. In addition, an equivalent area, described by a radius of $0.181 \mathrm{~m}$ loading circle, was found to represent the effect of the dual wheels on the roadway. This loading is confirmed by a study in case of axle overload. The interest of this new loading circle is to be able to determine the effect of the dual wheels in 2D. That said, a new geometry can represent the single axle with dual wheels, each side of which is equipped with a disk of radius $0.181 \mathrm{~m}$. The results obtained in this study should be the subject of further research in various directions. A study must be done on the loading 3 and the simplified loading of the single axle with 


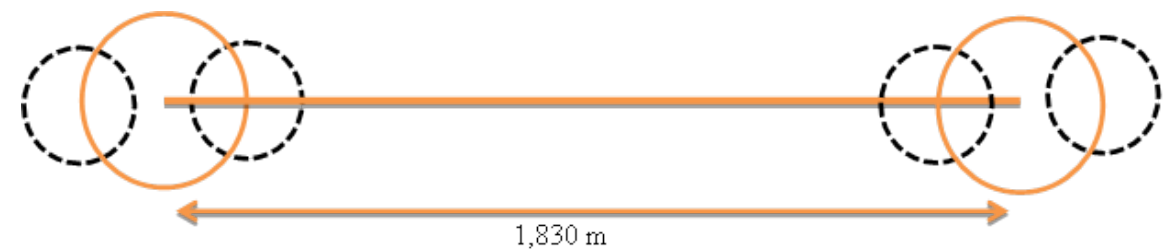

Figure 9. Simplified schematics of a single axle with the dual wheels.

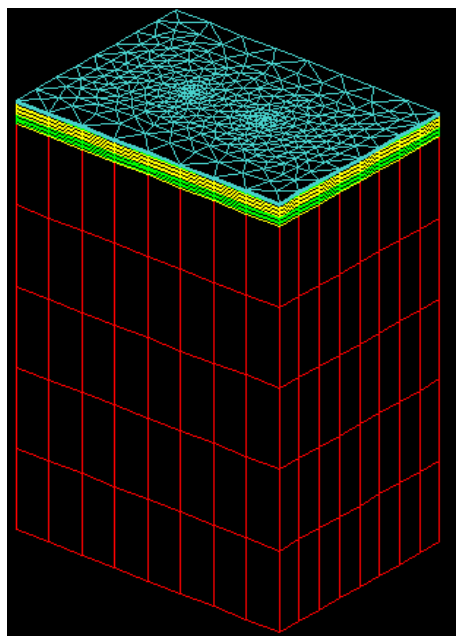

Figure 10. Mesh of the structure with simple axle loading simplified.

the dual wheels with other types of road to be able to pronounce on the validity of these types of loading.

\section{References}

[1] Huang, Y.H. (1969) Computation of Equivalent Single Wheel Load Using Layered System. Highway Research Board, HRR, No. 291.

[2] Hadi, A. (2009) Numerical Calculation for Equivalent Wheel Load (ESWL). College of Engineering, Al-Mustansiryiah University, Al Qadisiya Journal for Engineering sciences, Vol. 2.

[3] Diakhaté, M. (2007) Fatigue et comportement des couches d'accrochage dans les structures de chaussée. Thèse de doctorat Génie civil, Université de Limoges, Limoges.

[4] Thiam, B.B. (2016) Prise en compte de l'effet des roues jumelées sur le comportement des chaussées en graveleux latéritique. Mémoire de Master de recherche, UFR Science de l'Ingénieur-Université de Thiés.

[5] De Beer, M., Fisher, C. and Fritz, J.J. (1997) Determination of Pneumatic Tire/Pavement Interface Contact Stresses Under Moving Loads and Some Effects on Pavements with Thin Asphalt Surfacing Layers. Proceedings of the 8th International Conference on Asphalt Pavements, Seattle, 10-14 August 1997, Volume I, 179-227.

[6] Samb, F. (2014) Modélisation par éléments finis des chaussées en graveleux latéritiques traités ou non et application au dimensionnement mécanistique-empirique. Thèse de Doctorat Université de Thiès, Science de l'ingénieur.

[7] Dione, A. (2015) Estimation du module réversible des Graves non traités et modélisation par éléments finis des chaussées souples en vue d'un dimensionnement Mécanistique-Empirique. Thèse de doctorat Géotechnique routière, Université de 
Thiès, Sciences de l'ingénieur.

[8] Perret, J. and Dumont, A.G. (2004) Modélisation des charges de l'essieu. Rapport final parti 1, Mandat de recherche ASTRA 2000/421.

[9] Gillespie, D., Karanuhao, M., Sayers, W., Nasim, A., Hasen, W., Ehsan and Cabon, D. (1993) Effects of Heavy-Vehicle Characteristic on Pavement Responses and Performance. NCHRP Report 353. National Cooperative Highway Research Program, Transportation Research Board, Washington, p. 132.

[10] LPC Test Method No. 39 (1997) Road Studies, Pavement Surface Deformability, Execution and Operation of Measurements. 